\title{
The Model of the Distribution of Taxicab Resources
}

\author{
Ruiqi Zhan \\ Institute of Electrical and Electronic Engineering of North China Electric Power University, Baoding \\ 071000, China \\ 739131665@qq.com
}

\begin{abstract}
Key words: Dual Screening, Dual Prediction, Fractional Quantification, Neural Network.
\end{abstract}
\begin{abstract}
Based on the first question of problem B in the National Undergraduate Mathematical Modeling Contest of the Higher Education Cup in 2015, this model would quantify some relevant indexes to analyze the degree of supply and demand for taxicab resources.

In view of this question, this paper would estimate the distribution of taxi resource according to the analysis of the supply and demand, and establish the model of the Time and Neural Network. The assumed space-time condition is different periods and districts in one city. The supply quantity could be available through statistics, so the question is to work out the taxi demand and measure the degree of allocation of demand and supply according to the ratio of demand and actual supply (the arithmetic product of supply quantity and the rate of attendance) in the specific time and space. Firstly, to prove selecting indexes relevant to the demand for taxicabs through relativity analysis. The dimensionality of the variable could be reduced by filtering the main factors through principal component analysis. Secondly, to predict the data of principal components during 2009 2015 according to Time Series Analysis. Since the indexes would increase to the upper limit, the three Exponential Smoothing is more adoptable. The Neural Network prediction model would be established due to its high precision, and then the principal index during 2009 2015 could be input into it and the demand would be output. Finally, to estimate the demand in specific time and space and calculate the allocation degree of demand and supply on the ground of the population ratio in different periods and districts. The relativity analysis proves selected indexes relevant to the demand quantity. The principal component analysis filtered the population in downtown and operating distance. The time sequence predicts the principal component data, and the Neural Network forecasts the demand quantity. the distribution degree of demand and supply is a equilibrium value at $70 \%$. it would be not difficult for people to catch taxis if it is within $60 \%$ to $75 \%$. The selected indexes were based on dual analysis, and the prediction dual prediction, which reflects the high precision of this model.
\end{abstract}

\section{Introduction}

The taxi-taking software has emerged in taxi industry in such a era of Internet + , however, it still remains unknown what effects on earth it would act upon taxi drivers and the difficulties in taking taxis for the whole society. Our model is mainly to analyze the degree of supply and demand of taxicab resources and the effect degree of the subsidy scheme launched by software companies.

\section{The Neural Network model based on Time Sequence}

Problem analysis. the comprehension about the view of time and space: the time is the different period within one day, and the space is the different districts(commercial district, residential area, industrial area,etc.) in one city. And the problem should be working out the demand for taxicabs from a view of time and space in certain district, and measuring the allocation degree of demand and supply with the ratio of demand quantity and supply quantity.

The selected indexes could be proved to be relevant to the demand for taxis through the SPSS relativity analysis. The main indexes that influence the demand quantity in Nanchang city[1] could be figured out by principal component analysis. And the indexes of the relevant principal component data could be worked out through the time sequence model, and eventually, the demand for taxis during 2009 2015 would be predicted by the Neural Network. And then we take the time and space 
into consideration. Due to the assumption that the population proportion of different districts in a city remain unchanged[2] while the demand quantity in this district and its population proportion are in direct proportion, the demand for taxis in different districts could be worked out, which is the demonstration of the space view. Because of the assumption that the proportion of pedestrians in different periods remains unchanged[3], the demand in different periods could be worked out, which is the demonstration of the time view. The final data in the period and space during 2009 2015 would be chosen as a model to explain. The maintenance ratio of taxis and taxis' attendance should be taken into consideration, so the formula should be rectified: adding the attendance index. To estimate the allocation degree of supply and demand should be based on the ratio of the demand quantity in certain place or certain period and the actual supply quantity in that place or that period.

Model establishment. (1)the data related to the demand for taxis in different cities with the means of SPSS Relativity Analysis would be shown in the following Table 1. The relativity is analyzed through SPSS Relativity Analysis.

Table 1:the indexes Table of major domestic cities[4]

\begin{tabular}{|c|c|c|c|c|c|c|c|}
\hline & $\begin{array}{l}\text { the } \\
\text { Area }\end{array}$ & $\begin{array}{c}\text { the } \\
\text { Population }\end{array}$ & $\begin{array}{l}\text { Per Capito } \\
\text { GDP }\end{array}$ & $\begin{array}{c}\text { Bus } \\
\text { Number }\end{array}$ & $\begin{array}{l}\text { the Bus } \\
\text { Freight } \\
\text { Mileage }\end{array}$ & Price & $\begin{array}{c}\text { Taxi } \\
\text { Number }\end{array}$ \\
\hline $\begin{array}{l}\text { Shijiangzhu } \\
\text { ang }\end{array}$ & 455.8 & 200 & 25476.06 & 1865 & 727 & 9.2 & 6553 \\
\hline Hohhot & 2504 & 85 & 11788.62 & 423 & 327 & 9 & 6959 \\
\hline Changchun & 3583 & 292.8 & 21335.72 & 3024 & 739 & 8.1 & 12537 \\
\hline Shenyang & 3495 & 185 & 19406.97 & 3590 & 1553 & 10.34 & 16735 \\
\hline Harbin & 1637 & 329 & 18244.04 & 3165 & 721 & 11.8 & 11556 \\
\hline Nanjing & 976 & 264.9 & 27128.08 & 4362 & 7296 & 10.2 & 8956 \\
\hline Hangzhou & 683 & 128.76 & 38246.9 & 2038 & 656 & 12 & 6500 \\
\hline Fuzhou & 224 & 70 & 31582.03 & 1463 & 367 & 11.6 & 3473 \\
\hline
\end{tabular}

To analyze each index data with SPSS software and find out the Relativity Matrix. The Formula of the pearson relativity coefficient is:

$$
r=\frac{\sum_{i=1}^{n}\left(x_{i}-\bar{x}\right)\left(y_{i}-\bar{y}\right)}{\sqrt{\sum_{i=1}^{n}\left(x_{i}-\bar{x}\right)^{2} \sum_{i=1}^{n}\left(y_{i}-\bar{y}\right)^{2}}}
$$

(2)Principal Component Analysis

To utilize Principal Component Analysis based on the data of Nanchang city from 1997 to 2008 and reduce the variable dimension. 
Table 2: the Data of Nanchang city from 1997 to 2008

\begin{tabular}{ccccccc}
\hline Year & $\begin{array}{c}\text { Urban } \\
\text { Population }\end{array}$ & $\begin{array}{c}\text { the Mileage of } \\
\text { Urban } \\
\text { Operation Road }\end{array}$ & $\begin{array}{c}\text { the Expense of } \\
\text { Residents' Trips } \\
\text { and } \\
\text { Communication }\end{array}$ & GDP & $\begin{array}{c}\text { the Number } \\
\text { of Operating } \\
\text { Buses }\end{array}$ & $\begin{array}{c}\text { Freight } \\
\text { the }\end{array}$ \\
\hline 1997 & 155.74 & 1.0495 & 0.0304 & 3752067 & 604 & 2429 \\
1998 & 159.56 & 1.081 & 0.0393 & 3992606 & 68 & 2380 \\
1999 & 164.21 & 1.096 & 4.1801 & 4237630 & 735 & 2338 \\
2000 & 168.26 & 1.2385 & 0.0499 & 4651411 & 867 & 2300 \\
2001 & 172.45 & 1.2812 & 0.0719 & 5245868 & 952 & 2144 \\
2002 & 180.99 & 1.3503 & 0.0817 & 6019950 & 1160 & 2132 \\
2003 & 196.37 & 1.4194 & 0.0936 & 7054437 & 447 & 2120 \\
2004 & 203.73 & 1.9682 & 0.1033 & 85111066 & 1650 & 2110 \\
2005 & 214.52 & 2.517 & 0.1276 & 10077025 & 1824 & 2100 \\
2006 & 221.32 & 2.668 & 0.1347 & 11838973 & 2229 & 2091 \\
2007 & 222.79 & 2.819 & 0.2337 & 13898920 & 2448 & 2083 \\
2008 & 223.09 & 2.97 & 0.3028 & 16600847 & 2518 & 2076 \\
\hline
\end{tabular}

If the contribution rate of the analyzed component rises to $80 \%$, it would be the principal component which could replace all the other components.

(3) Time Sequence Model

Due to the assumption of different upper limits of each index, we adopt the cubic exponential smoothing method of Time Sequence to predict the parameters of the principal components during 2009 2015.

(4) Neural Network

On account of the high precision of Neural Network, it is wise to adopt BP Neural Network algorithm to figure out the demand for taxicabs during 2009 2015.

The condition,the parameter $\alpha>0$ in the activation function $\varphi(v)=\frac{1}{1+\exp (-\alpha v)}$ should be satisfied so as to control the slope. The input signal is the main indicator through principal component analysis, and the output signal is the demand for taxicabs in this city.

(5)Provided that the population proportion remains unchanged, and the population proportion in residential, commercial, and industrial districts is respectively $50 \%, 5 \%, 10 \%$, the demand for taxicabs in different districts should be: $\quad N_{I}=n_{i} * D$

Provided that the peak hours of different proportions in sequence are:7: 30-9: 00、16: 30-19: 00、21: $00-22: 00$. And the normal hours is: the proportion of the extra hours and the residents' trips on the same day

$0.15+0.09+0.04+0.095+0.085+0.02=0.48$

Therefore, the demand for taxicabs in different districts should be: $M_{I}=m_{i} * D$

(6)the supply quantity of taxicabs: $G=S \times \alpha$; "S" stands for the actual amount of taxicabs the city owned, and $\alpha$ should be $80 \%$, then the degree of supply and demand could be estimated on the ground of the passenger load factor. $\beta=\frac{D}{G}$

It is a best allocation degree for $\beta$ to float in the vicinity of 0.7 . If it ranges within $60-75 \%$, it is a demonstration that the difficulty in taking taxis is not severe, and if it is below $60 \%$, it indicates that the difficulty in taking taxis doesn't exist and the the supply quantity of taxis exceeds the demand quantity. If it is above $75 \%$, that means the problem of taking taxis is quite severe. 


\section{Model Solution.}

(1)SPSS Relativity Analysis

Table 3:the Correlation Coefficients of each Index

\begin{tabular}{cccccc}
\hline The Area & $\begin{array}{c}\text { The } \\
\text { Population }\end{array}$ & $\begin{array}{c}\text { Per } \\
\text { Capito } \\
\text { GDP }\end{array}$ & $\begin{array}{c}\text { The } \\
\text { Number of } \\
\text { Buses }\end{array}$ & $\begin{array}{c}\text { The Mileage of } \\
\text { Public Transport } \\
\text { Freight }\end{array}$ & Price \\
\hline 0.736 & 0.612 & 0.662 & 0.574 & 0.575 & 0.665 \\
\hline
\end{tabular}

(2) Principal Component Analysis

The contribution rate of each index:

Table 4: The Contribution Rate of Each Index

\begin{tabular}{cccccc}
\hline $\begin{array}{c}\text { Urban } \\
\text { Population }\end{array}$ & $\begin{array}{c}\text { The Mileage of } \\
\text { Urban Operation } \\
\text { Road }\end{array}$ & $\begin{array}{c}\text { The Expense of } \\
\text { Residents Trips } \\
\text { and } \\
\text { Communication }\end{array}$ & GDP & $\begin{array}{c}\text { The Number } \\
\text { of Operating } \\
\text { Buses }\end{array}$ & Freight \\
\hline 0.636 & 0.158 & 0.1428 & 0.0485 & 0.0136 & 0.0011 \\
\hline
\end{tabular}

Then the selected indexes are: population in downtown, The mileage of Urban operation road

(3)Time Sequence Model

The data during 2009 2015 figured out with the cubic exponential smoothing method respectively are:(year, urban population/ten thousand, the mileage of urban operating road $/ \mathrm{km}$ )2009, 223.04, $3159.2)(2010,220.5,3111.6)(2011,216.52,3446.4)(2012,211.08,3563.8)$ (2013, $204.2,3663.6)(2014,195.86,3745.9)(2015,186.07,3810.7)$

(4)Neural Network

The demand for taxicabs during 2009 2015 worked out with Neural Network is:(year, the demand for taxis $)(2009,3739.7)(2010,3730.4)(2011,3903.7)(2012,3984.2) \quad(2013,3980.9)$

$(2014,3354.1) \quad(2015,3986.5)$

(5)the Time-Space view

The demand for taxicabs in different districts based on time-space view. We just take the data during 2009 2015 as an example, the demand for taxicabs based on time-space view is:

Table 5: the demand for Taxicabs in Different Districts

\begin{tabular}{cccc}
\hline Year & Commercial District & Industrial District & $\begin{array}{c}\text { Residential } \\
\text { District }\end{array}$ \\
\hline 2014 & 177.705 & 355.41 & 1777.05 \\
2015 & 154.325 & 308.65 & 1543.25 \\
\hline
\end{tabular}

The demand for taxicabs in different periods. We just take the data during 2009 2015 as an example, the demand for taxicabs based on time-space view is:

Table 6:The Demand for Taxicabs in Different Periods

\begin{tabular}{lll}
\hline Year & In Peak Hours & In Normal Hours \\
\hline 2014 & 1705.968 & 1848.132 \\
2015 & 1481.52 & 1604.98 \\
\hline
\end{tabular}

(6) The supply quantity in each district and each period could be calculated out with the help of specific observation instruments, and the computational Formula could be derived from the Formula 9 , therefore, we could estimate the specific allocation degree of the demand and supply of taxicabs in different periods and different districts and the exact severity of the problem of taking taxis in society.

\section{Summary}

According to the SPSS Relativity Analysis, the correlation coefficients of different indexes are below 0.5 , and all the selected indexes are related to the demand for taxicabs. It could be learned from Principal Component Analysis that the cumulative contribution rate of urban population and the mileage of urban operation road amounts to over $80 \%$ with the downtown and the operation mileage taken as the principal components. The index data is predicted by Time Sequence. Based on the Neural Network, the demand for taxicabs could be figured out from the data of two major principal components during 
2009 2015. The actual value of Neural Network is identical with the predictive value, namely, the actual demand could be estimated accurately according to the demand for taxicabs worked out with Neural Network. The time-space view is indicated from the different districts and different periods in one city, and the specific value of in specific periods and districts is correspondingly worked out with the help of population proportion, when it is $70 \%$, that means balance between supply and demand. When it is within $60-75 \%$, that means the problem of taking taxicabs is not severe.

\section{References}

[1] Yang Jianrong, the Analysis of Features of Taxi Industries in Domestic Cities and the Model Establishing of the Demand Prediction-Taking Nanchang City as An Example[D], a master dissertation of Nanchang University, 2009, 63.

[2]Information on https://www.haosou.com/s?q=\%E5\%9F\%8E\%E5\%B8\%82\%E5\%95\%86\%E4\% B8\%9A\%E5\%8C\%BA\%E6\%AF\%94\%E4\%BE\%8B\&src=srp\&fr=lm\&psid=0f46df90aeee96e53a9 284ed4a5ffa03\&ls=n36a7f6a197. 2015/9/12.

[3] Che lan, the Situation of the Taxi Development in Cities and the Demand Prediction [J], Shanxi Science and Technology, 6, 89-91, 2006.

[4] Yang Changtao, the Research on the Inventory of Urban Taxicabs[D], a master's dissertation of South China University of Technology,32-36, 2011. 